\title{
INFLUENCE OF SYNTHESIS PROCESS ON THE COLOUR PROPERTIES OF MIXED OXIDE PIGMENT Bi ${ }_{1.5} \mathrm{Zn}_{0.5} \mathrm{Ce}_{2} \mathrm{O}_{7}$
}

\author{
\#KATEŘINA TĚŠITELOVÁ, PETRA ŠULCOVÁ, MILENA KAUFMANNOVÁ \\ Department of Inorganic Technology, Faculty of Chemical Technology, University of Pardubice, \\ Studentská 95, 53210 Pardubice, Czech Republic \\ "E-mail: katerina.tesitelova@student.upce.cz
}

Submitted March 31, 2016; accepted June 29, 2016

\begin{abstract}
Keywords: Inorganic pigments, Mixed oxide pigments, Bismuth compounds, Colour properties, Yellow shade
The synthesis of a new inorganic pigment $\mathrm{Bi}_{1.5} \mathrm{Zn}_{0.5} \mathrm{Ce}_{2} \mathrm{O}_{7}$ is reported. The pigment was prepared by conventional solid-state reaction (SSR), suspension mixing (SM) and precipitation reaction $(P R)$ with the goal of creating an environmentally benign pigment. The selected samples were characterized by X-ray diffraction analysis. Focusing on pigmentary applications, specific properties of the samples were evaluated, such as colour parameters and particle size distribution. Dark yellow hues were obtained by using SSR and SM after the application samples into the organic binder in mass tone. The PR method was found to be the most suitable for the formation of dark yellow shades in the ceramic glaze. Based on obtained results, $\mathrm{Bi}_{1.5} \mathrm{Zn}_{0.5} \mathrm{Ce}_{2} \mathrm{O}_{7}$ could be considered as a perspective yellow pigment for colouring organic binder systems and ceramic glaze.
\end{abstract}

\section{INTRODUCTION}

Nowadays it is a current need to develop environmental-friendly inorganic pigments to replace pigments containing toxic elements such as $\mathrm{Cd}, \mathrm{Co}, \mathrm{Cr}, \mathrm{Hg}, \mathrm{Pb}$, $\mathrm{Sb}$ and $\mathrm{Se}$ that are hazardous to health and environment. Most of the yellow inorganic pigments today are based on cadmium, lead, chromium (IV), i.e. heavy metalbased inorganic chemicals, which may have harmful effects on the environment and human health and the use of which is restricted by law in a number of countries $[1,2]$.

A large group of industrially used yellow and orange colorants consists of chromate pigments. The most important chromate pigments include lead chromate (chrome yellow) and lead molybdate pigments (molybdate orange and molybdate red) whose colours range from light lemon yellow to red with a blue hue. Chrome yellow pigments consist of $\mathrm{Pb}(\mathrm{Cr}, \mathrm{S}) \mathrm{O}_{4}$, and chrome orange is a basic lead chromate $\mathrm{PbCrO}_{4} \cdot \mathrm{PbO}$. Molybdate red and molybdate orange are mixedphase pigments with formula $\mathrm{Pb}(\mathrm{Cr}, \mathrm{Mo}, \mathrm{S}) \mathrm{O}_{4}$. Chrome pigments are widely used in paints, coatings and plastics. They are characterized by brilliant colour hues, good tinting strength, hiding power, lightfastness and weather resistance. Another important group of yellowshade pigments is represented by compounds containing cadmium, i.e. cadmium pigments. Cadmium yellow consists of pure cadmium sulphide (golden yellow colour) or mixed crystals of zinc and cadmium sulphide, $(\mathrm{Cd}, \mathrm{Zn}) \mathrm{S}$, in which up to one-third of the cadmium can be replaced by zinc. The colour of cadmium pigments can be controlled via the composition and the size of the primary particles. These pigments provide an excellent hiding power and have found application in the colouring of plastics and ceramics. Widely used dyes are bismuth vanadate pigments. The composition of commercial grade bismuth vanadate pigments varies greatly, extending from pure $\mathrm{BiVO}_{4}$ to mixed pigment $\mathrm{BiVO}_{4}-\mathrm{Bi}_{2} \mathrm{MoO}_{6}$, which exhibits brilliant greenish yellow to reddish yellow shades. In order to improve product properties, the pigments may contain several percent of inorganic stabilizers, for example silicates. Bismuth vanadate pigments are used for lead- and chromate-free, brilliant yellow, orange, red and green shades for original automotive coatings, repair coatings and industrial coatings of good quality. These pigments with high colour intensity, brightness and hiding power have benefited from the decline in the use of lead chromate and cadmium pigments. Due to the high costs of raw materials are in the higher price range of inorganic pigments $[3,4]$.

It is obvious that most of the industrially used yellow inorganic pigments contain a toxic metal such as cadmium, lead and hexavalent chromium, contributing to environmental contamination and representing a risk to human health. Additionally, the regulations for the protection of the environment and human health have resulted in efforts to develop more environmentally acceptable inorganic compounds. This has stimulated, during the last decade, research to develop a new high performance, environmentally friendly and economically viable materials, which would be able to replace the toxic inorganic pigments in various applications. 
Compounds on the base of $\mathrm{Bi}_{2} \mathrm{O}_{3}$ seem to be interesting due to their colour which is varying from yellow to orange shades. Bismuth oxide has a variety of desirable properties, including a high bandgap $(2.00-3.96 \mathrm{eV})$, a high refractive index and photoluminescence. This oxide is applied in a range of fields such as solid oxide fuel cells, gas sensors, high temperature superconductor materials, functional ceramics and catalysis $[5,6]$. Pure bismuth oxide, $\mathrm{Bi}_{2} \mathrm{O}_{3}$ is known to exhibit four crystallographic polymorphs. A monoclinic $\alpha$ form stable below $730^{\circ} \mathrm{C}$, a cubic $\delta$ form stable from $730^{\circ} \mathrm{C}$ to the melting point and a metastable tetragonal $\beta$ form and $\gamma$ form which appear during cooling of the $\delta$ form. The phase $\delta-\mathrm{Bi}_{2} \mathrm{O}_{3}$ is stable between $730^{\circ} \mathrm{C}$ and the melting point $824^{\circ} \mathrm{C}[7,8]$.The high-temperature phase of bismuth sesquioxide $\delta-\mathrm{Bi}_{2} \mathrm{O}_{3}$ has been intensively studied because of its high oxygen-ion conductivity. The structure of the $\delta$-phase is based on a face-centered cubic cation sublattice and can be described as a defective fluorite structure where $1 / 4$ of the anion sites are vacant. This high oxygen vacancy concentration gives rise to the high oxygen-ion mobility. The $\delta$-phase may be stabilized below room temperature by doping with some transition metal and rare earth. It is also possible to use a combination of oxides, so-called double doping, to obtain the $\delta$ fluorite type phase. Fluorite-type $\delta$-phase materials display very high oxide ion conductivity which is attributed to the highly polarizable $\mathrm{Bi}^{3+}$ cations and the highly disordered structure of the sublattice [9-12].

The main attention in our research was focused on the yellow shade pigment synthesis based on $\mathrm{Bi}_{2} \mathrm{O}_{3}$ doped by zinc and cerium ions. This pigment $\left(\mathrm{Bi}_{1.5} \mathrm{Zn}_{0.5} \mathrm{Ce}_{2} \mathrm{O}_{7}\right)$ is expected to become a new high-performance ecological pigment and a worthy replacement for the currently applied toxic compounds. Our goal was to suggest and elaborate the different synthesis conditions of the studied pigment, investigate its colour possibilities and verify its applicability. The influence of the preparation and calcination temperature on the pigment properties is systematically studied as well.

\section{EXPERIMENTAL}

\section{Preparation of sample}

The composition based on $\mathrm{Bi}_{1.5} \mathrm{Zn}_{0.5} \mathrm{Ce}_{2} \mathrm{O}_{7}$ was prepared by three different methods, i.e. solid-state reaction (SSR), suspension mixing (SM) and precipitation reaction (PR). In case of the first method of synthesis (SSR) the corresponding oxides were used: $\mathrm{Bi}_{2} \mathrm{O}_{3}(99.8 \%$ purity, Lachema Pliva, a.s., CZ), ZnO (> $99 \%$ purity, The Shepherd Color Company, USA) and $\mathrm{CeO}_{2}(99.9 \%$ purity, ML-Chemica, CZ). The raw materials were blended in the proper stoichiometric compositions and then manually homogenized in a porcelain mortar for $15 \mathrm{~min}$. The homogeneous mixture was calcined in corundum crucibles in an electric furnace at the temperatures from 800 to $1000^{\circ} \mathrm{C}$ with the heating rate $10^{\circ} \mathrm{C} \cdot \mathrm{min}^{-1}$. The calcination was maintained in isothermal conditions for $2 \mathrm{~h}$ with the step $50^{\circ} \mathrm{C}$. The synthesized samples were left to cool at room temperature after each heating stage and subsequently ground in a porcelain mortar.

The second way of preparation of the study pigment was based on the suspension mixing of the initial reagents (SM). As initial components were used: $\mathrm{Bi}\left(\mathrm{NO}_{3}\right)_{3} \cdot 5 \mathrm{H}_{2} \mathrm{O}$ (99 \% purity, Lachema Pliva, a.s., $\mathrm{CZ}$ ), $\mathrm{ZnSO}_{4} \cdot 7 \mathrm{H}_{2} \mathrm{O}$ ( $>99 \%$ purity, Lachema, a.s., $\mathrm{CZ}$ ) and $\mathrm{Ce}\left(\mathrm{SO}_{4}\right)_{2} \cdot 4 \mathrm{H}_{2} \mathrm{O}$ ( $97 \%$ purity, ML-Chemica, CZ). Sodium carbonate $\mathrm{Na}_{2} \mathrm{CO}_{3}(>99 \%$ purity, Lachema Pliva, a.s., $\mathrm{CZ}$ ) had to be added to the mixture for the removal of sulphates. SM can be presented as a two-step process. In the first step, the starting compounds, $\mathrm{Na}_{2} \mathrm{CO}_{3}$ and foaming agents, i.e. fumaric acid $\mathrm{C}_{4} \mathrm{H}_{4} \mathrm{O}_{4}(99 \%$ purity, Acros Organics, USA) and urea $\mathrm{CH}_{4} \mathrm{~N}_{2} \mathrm{O}(99.5 \%$ purity, Lachema Pliva, a.s., CZ), were wet homogenised in a porcelain mortar. The aqueous suspension was subsequently put on a preheated steel plate at the temperature of $400^{\circ} \mathrm{C}$ and thermally treated for a few minutes. The powdered semi-product obtained was subjected to calcination in an electric furnace at the required temperature in the same conditions as by solid state reaction (second step of the preparation). After cooling, the sample was washed with boiling water, filtered and dried at $100^{\circ} \mathrm{C}$.

The third synthesis route was precipitation. In this case, the same starting powder components have been used as for method SM. The compound $\mathrm{Bi}\left(\mathrm{NO}_{3}\right)_{3} \cdot 5 \mathrm{H}_{2} \mathrm{O}$ was dissolved under continuous stirring in a solution of nitric acid, $\mathrm{ZnSO}_{4} \cdot 7 \mathrm{H}_{2} \mathrm{O}$ and $\mathrm{Ce}\left(\mathrm{SO}_{4}\right)_{2} \cdot 4 \mathrm{H}_{2} \mathrm{O}$ were dissolved in distilled water. The obtained solutions of starting materials with a dissolving liquid were mixed and precipitated by slow addition of saturated solution of $\mathrm{NaOH}$. The formed precipitate was filtered, washed with distilled water to neutral $\mathrm{pH}$ of the filtrate and dried at $100^{\circ} \mathrm{C}$. The subsequent calcination of the dried sample was carried out at the same temperatures and conditions as in the case of the SSR and SM methods.

All prepared pigments were applied to an organic matrix (dispersive acrylic paint Parketol, Balakom, a.s., $\mathrm{CZ}$ ) in mass tone. The mass tone denotes the colour obtained when the pigmented medium is applied as a lyer that does not hide the substrate completely (e.g. on a white substrate) [3]. Approximately $1 \mathrm{~g}$ of the powder sample and $1.5 \mathrm{~cm}^{3}$ of the binder were blended in an agate mortar. The created paste was dashed by a steel spatula on the white nonabsorbing paper. Layers of paint film were created by a pulling of the Bird applicator slit width of $100 \mu \mathrm{m}$. For testing in ceramic glaze, the pigments were also applied into medium-temperature borate-silicate ceramic glaze G 07091 (Glazura, s.r.o., Roudnice nad Labem, CZ). The aqueous suspension containing 10 mass \% of a pigment and 90 mass \% of the glaze was applied by a brush to dry white ceramic fragments, which were dried at room temperature and then calcined in an electric furnace at $1000^{\circ} \mathrm{C}$ at a heating rate of $10^{\circ} \mathrm{C} \cdot \mathrm{min}^{-1}$ for $15 \mathrm{~min}$. 
Characterization of sample

Phase analysis of coloured samples was performed by X-ray powder diffraction using a D8 Advance diffractometer (Bruker AXS, GB) equipped with a goniometer of $17 \mathrm{~cm}$ in the $2 \theta$ range of $10-80^{\circ} . \mathrm{Cu} \mathrm{K}_{\alpha 1}$ $(\lambda=0.15418 \mathrm{~nm})$ radiation was used for angular range of $2 \theta<35^{\circ}$ and $\mathrm{Cu} \mathrm{K} \mathrm{K}_{\alpha 2}(\lambda=0.15405 \mathrm{~nm})$ for the range of $2 \theta>35^{\circ}$. A scintillation detector was used [13].

Particle size distribution of the samples was measured using a laser scattering system Mastersizer 2000/MU (Malvern Instruments, UK) and calculated on the basis of Fraunhofer diffraction. The granulometer used is a highly integrated laser measuring device for analysis of particle size in the range from 0.02 to 2000 $\mu \mathrm{m}$. The system evaluates the particle size using red light (He-Ne laser, $\lambda=633 \mathrm{~nm}$ ) and blue light (solidstate light source, $\lambda=466 \mathrm{~nm}$ ). The pigments were ultrasonically homogenized in $\mathrm{Na}_{4} \mathrm{P}_{2} \mathrm{O}_{7}$ solution ( $c$ $=0.15 \mathrm{~mol} \cdot \mathrm{dm}^{-3}$ ) for $120 \mathrm{~s}$ and measured. The results are automatically calculated as average and presented as values of $d_{10}, d_{50}, d_{90}$ and parameter span, which is calculated according to the formula span $=\left(d_{90}-d_{10}\right) / d_{50}$.

The colour properties of the samples were evaluated by measurement of spectral reflectance in the visible region of light (400 - $700 \mathrm{~nm}$ ) using a spectrophotometer (ColorQuest XE, HunterLab, USA). The measurement conditions were the following: $10^{\circ}$ standard observer, an illuminant $\mathrm{D}_{65}$ and $d / 8^{\circ}$ measuring geometry. The Commission Internationale de 1'Eclairage CIE $L^{*} a^{*} b^{*}$ 1976 colour scales were used for the assessment of the colour properties of the pigments. In this system, $L^{*}$ is the colour lightness $\left(L^{*}\right.$ is 0 for black and $L^{*}$ is 100 for white), $a^{*}$ is the green $(-) /$ red (+) axis, $b^{*}$ is the blue (-)/ yellow $(+)$ axis. For each colorimetric parameter of the sample, the measurement was done thrice and the average value was chosen as its result. A thorough description of the colour is done by recalculation of value $C$ (Chroma), which determines the saturation of the colour and is calculated according to the formula $C=\left(a^{* 2}+b^{* 2}\right)^{1 / 2}$.

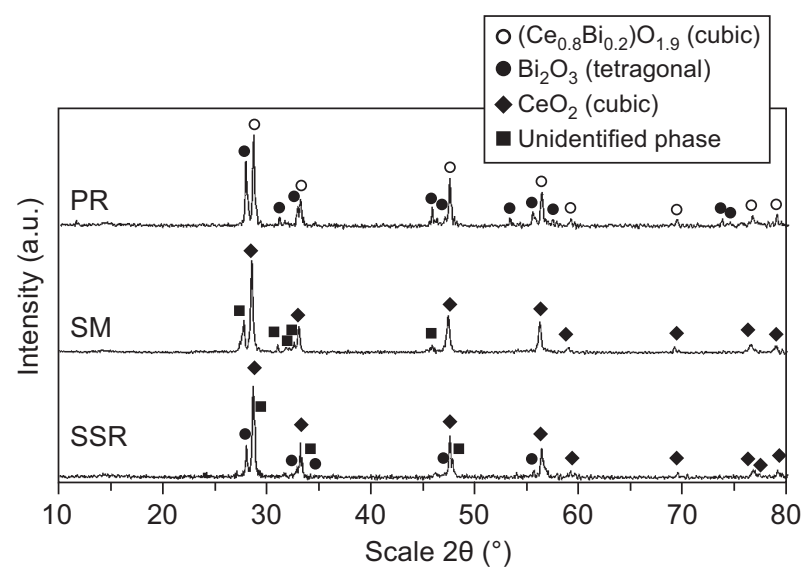

Figure 1. Diffractograms of $\mathrm{Bi}_{1.5} \mathrm{Zn}_{0.5} \mathrm{Ce}_{2} \mathrm{O}_{7}$ pigments prepared by SSR, SM and $\mathrm{PR}\left(1000^{\circ} \mathrm{C}\right)$.
The colour hue of pigments is also expressed by the hue angle $H^{\circ}$ that has interval $0^{\circ}-360^{\circ}$, and for red colour, it has value $350^{\circ}-35^{\circ}$, for orange $35^{\circ}-70^{\circ}$, for yellow $70^{\circ}-105^{\circ}$, for green $105^{\circ}-195^{\circ}$, for blue $195^{\circ}-285^{\circ}$ and for violet $285^{\circ}-350^{\circ}[14,15]$.

The band gap energy $E_{\mathrm{g}}$ was determined from reflectance spectra using the Kubelka-Munk function which is given by $\mathrm{K}-\mathrm{M}=(1-R)^{2} / 2 R$, where $R$ is the reflectance value. The values of $\mathrm{K}-\mathrm{M}$ coefficients were obtained from measuring with the help of ColourQuest $\mathrm{XE}$ and the value of the wavelength is substituted in the formula $\mathrm{E}(\mathrm{eV})=1236 /$ wavelength $(\mathrm{nm})$ [16].

\section{RESULTS AND DISCUSSION}

The pigment $\mathrm{Bi}_{1.5} \mathrm{Zn}_{0.5} \mathrm{Ce}_{2} \mathrm{O}_{7}$ was studied by powder $\mathrm{X}$-ray diffraction analysis (Figure 1). For comparing all methods of preparation used (SSR, SM and PR) only one temperature of calcination, i.e. $1000^{\circ} \mathrm{C}$ was chosen. In case of X-ray diffraction analysis, the pyrochlore compounds occur as defective fluorite and can be exchanged for cerium oxide because the pyrochlore structure is closely related to the fluorite structure and can be thought of as a cation-ordered anion deficient fluorite lattice, in which the cations form a face-centered cubic array [17]. In the database for the evaluation of the composition studied compounds samples were often compared with cubic $\mathrm{CeO}_{2}$ (lattice parameter $a=$ $0.5411 \mathrm{~nm}$ ) [18]. It has been verified, that the pigment prepared by solid state reaction contains three phases. The fluorite-type of $\mathrm{CeO}_{2}$ (JPDF number 04-013-4361) structure of the sample with cubic symmetry with lattice parameter $a=0.5411 \mathrm{~nm}$ was identified besides free tetragonal $\mathrm{Bi}_{2} \mathrm{O}_{3}$ (JPDF number 04-007-1443) with lattice parameter $a=0.7741 \mathrm{~nm}$. On this XRD pattern, the unidentified peak which was not found in the available database was also recorded. This unidentified peak probably corresponds to the formation of a new phase. In case of SM two peaks were observed. The first phase corresponds to cubic $\mathrm{CeO}_{2}$ in space group symmetry Fm 3 m. The second phase was not identified. The sample prepared by precipitation was two-phased because besides the peaks of the cubic phase of $\left(\mathrm{Ce}_{0.8} \mathrm{Bi}_{0.2}\right) \mathrm{O}_{1.9}$ (JPDF number 01-080-6621) with lattice parameter $a=0.5417 \mathrm{~nm}$ also a secondary phase of $\mathrm{Bi}_{2} \mathrm{O}_{3}$ with tetragonal symmetry was detected [19].

The aim of the research was to find the best conditions for the preparation of the pigment with formula $\mathrm{Bi}_{1.5} \mathrm{Zn}_{0.5} \mathrm{Ce}_{2} \mathrm{O}_{7}$ and to compare the influence of different methods of preparation on the colour properties after application of pigment into an organic matrix and a ceramic glaze.

The influence of the calcination temperature on the colour properties of the pigment $\mathrm{Bi}_{1.5} \mathrm{Zn}_{0.5} \mathrm{Ce}_{2} \mathrm{O}_{7}$ prepared by solid state reaction (SSR) and applied to the organic matrix in mass tone was investigated. 
From Table 1 it follows that increasing the calcination temperature decreases the values $C$ up to $900^{\circ} \mathrm{C}$. The highest saturation $C$ was obtained by firing at a temperature $950^{\circ} \mathrm{C}$. Increasing temperature causes also an increase of bandgap energy values $E_{g}(\mathrm{eV})$ up to $900^{\circ} \mathrm{C}$ followed by a decrease at higher temperature. This fact is confirmed by the change of the colour from yellow to dark yellow-orange. On the other hand values of the hue angle are growing up to temperature $900^{\circ} \mathrm{C}$. The hue angle values of the pigment $\mathrm{Bi}_{1.5} \mathrm{Zn}_{0.5} \mathrm{Ce}_{2} \mathrm{O}_{7}$ lie in the yellow region of the cylindrical colour space ( $H^{\circ}=70-105$ for yellow). Based on the investigation and evaluation of colour properties of the samples, the temperature $950^{\circ} \mathrm{C}$ is the best for the preparation of dark yellow colour, because the coordinate $L^{*}$ has the lowest value (73.99) and the value of $H^{\circ}(80.22)$ approximates the area that is represented by an orange shade. This sample also disposes by the highest value of the colour coordinate $b^{*}$ (63.62), which corresponds to the contribution of yellow. Table 2 demonstrates the influence of calcination temperature on the colour properties of pigments, which were applied into ceramic glaze. The influence of the calcination temperature is not as expressive as in the case of the application into an organic matrix. The samples have markedly lower values of saturation $C$, which lie in a narrow interval from $35-38$, and the yellow parameter $\left(b^{*}\right)$. The green hue of the samples as denoted by the colour coordinate $a^{*}$ shows a slight increase up to temperature $950{ }^{\circ} \mathrm{C}$ and decreases thereafter. This fact is confirmed by the high values of angle $H^{\circ}$ that are located in a very narrow interval (approx. $96^{\circ}-98^{\circ}$ ). Generally, this kind of application provides light yellow-green shades, which corresponds to the high values of brightness $L^{*}$.

Table 1. Effect of calcination temperature on colour properties of pigment $\mathrm{Bi}_{1.5} \mathrm{Zn}_{0.5} \mathrm{Ce}_{2} \mathrm{O}_{7}$ prepared by SSR and applied into organic matrix in mass tone.

\begin{tabular}{lcrcccc}
\hline$T\left({ }^{\circ} \mathrm{C}\right)$ & $L^{*}$ & \multicolumn{1}{c}{$a^{*}$} & $b^{*}$ & $C$ & $H^{\circ}$ & $E_{g}(\mathrm{eV})$ \\
\hline 800 & 86.99 & 7.56 & 61.65 & 62.11 & 83.01 & 2.71 \\
850 & 80.88 & 6.44 & 56.74 & 57.10 & 83.52 & 2.72 \\
900 & 85.97 & 3.66 & 56.75 & 56.87 & 86.31 & 2.74 \\
950 & 73.99 & 10.97 & 63.62 & 64.56 & 80.22 & 2.48 \\
1000 & 70.68 & 6.89 & 48.80 & 49.28 & 81.96 & 2.55 \\
\hline
\end{tabular}

Table 2. Effect of calcination temperature on colour properties of pigment $\mathrm{Bi}_{1.5} \mathrm{Zn}_{0.5} \mathrm{Ce}_{2} \mathrm{O}_{7}$ prepared by SSR and applied into ceramic glaze.

\begin{tabular}{lcccccc}
\hline$T\left({ }^{\circ} \mathrm{C}\right)$ & $L^{*}$ & $a^{*}$ & $b^{*}$ & $C$ & $H^{\circ}$ & $E_{g}(\mathrm{eV})$ \\
\hline 800 & 93.70 & -5.14 & 35.12 & 35.49 & 98.33 & 2.90 \\
850 & 93.47 & -4.59 & 34.48 & 34.78 & 97.58 & 2.88 \\
900 & 92.57 & -4.31 & 37.32 & 37.57 & 96.59 & 2.85 \\
950 & 84.09 & -3.58 & 36.93 & 37.10 & 95.54 & 2.81 \\
1000 & 84.03 & -3.94 & 38.10 & 38.30 & 95.90 & 2.81 \\
\hline
\end{tabular}

Results from samples prepared by suspension mixing (SM) are noticed in Table 3. The pigments applied into organic matrix provided higher values of colour coordinate $b^{*}$ and saturation $C$ in comparison with the previous method of preparation (SSR). Positive values of the colour coordinate $a^{*}$ were achieved in the temperature range $800-950^{\circ} \mathrm{C}$. Only the highest temperature caused a shift of colour coordinate into a negative area $\left(a^{*}=-0.22\right)$ and in the resulting shade of sample the presence of green colour is observed. It can be observed from the table that increasing temperature enhances the values of brightness $L^{*}$, hue angle $H^{\circ}$ and bandgap $E_{g}$. Interesting dark yellow colour was achieved at the lowest temperatures $800^{\circ} \mathrm{C}$. The great lightening of yellow tint caused the application of pigment into a ceramic glaze (Table 4$)$. The colour coordinate $a^{*}$ exhibits a negative values in the whole temperature range, which correspond to the green contribution in the resulting shades. The growing temperature of calcination leads to an increase of saturation $C$ and the colour coordinate $b^{*}$. The prepared samples are characterized by very similar light yellow-green tones.

A third process for preparing of pigment $\mathrm{Bi}_{1.5} \mathrm{Zn}_{0.5}$ $\mathrm{Ce}_{2} \mathrm{O}_{7}$ provided yellow-brown-green shades after the application of samples into the organic binder (Table 5). The darkest colour was obtained for the temperature $950^{\circ} \mathrm{C}$. The calcination temperature increase up to $900^{\circ} \mathrm{C}$ led to growth in values of hue angle $H^{\circ}$. Decreasing course of values with increasing temperature records a brightness $L^{*}$ and bandgap $E_{g}$. In this case, the colour coordinate $b^{*}$ is characterized by low values, which are located in the interval from 30 to 40 . Generally, this method of synthesis does not provide the desired saturated yellow sample of $\mathrm{Bi}_{1.5} \mathrm{Zn}_{0.5} \mathrm{Ce}_{2} \mathrm{O}_{7}$ pigment. The colour

Table 3. Effect of calcination temperature on colour properties of pigment $\mathrm{Bi}_{1.5} \mathrm{Zn}_{0.5} \mathrm{Ce}_{2} \mathrm{O}_{7}$ prepared by $\mathrm{SM}$ and applied into organic matrix in mass tone.

\begin{tabular}{lcccccc}
\hline$T\left({ }^{\circ} \mathrm{C}\right)$ & $L^{*}$ & $a^{*}$ & $b^{*}$ & $C$ & $H^{\circ}$ & $E_{g}(\mathrm{eV})$ \\
\hline 800 & 81.92 & 9.34 & 67.34 & 67.98 & 82.10 & 2.62 \\
850 & 80.26 & 9.87 & 66.33 & 67.06 & 81.54 & 2.61 \\
900 & 83.02 & 5.22 & 67.56 & 67.76 & 85.58 & 2.63 \\
950 & 83.70 & 2.80 & 65.69 & 65.75 & 87.56 & 2.65 \\
1000 & 84.15 & -0.22 & 60.21 & 60.21 & 90.21 & 2.67 \\
\hline
\end{tabular}

Table 4. Effect of calcination temperature on colour properties of pigment $\mathrm{Bi}_{1.5} \mathrm{Zn}_{0.5} \mathrm{Ce}_{2} \mathrm{O}_{7}$ prepared by $\mathrm{SM}$ and applied into ceramic glaze.

\begin{tabular}{lcccccc}
\hline$T\left({ }^{\circ} \mathrm{C}\right)$ & $L^{*}$ & $a^{*}$ & $b^{*}$ & $C$ & $H^{\circ}$ & $E_{g}(\mathrm{eV})$ \\
\hline 800 & 88.02 & -5.21 & 37.24 & 37.60 & 97.96 & 2.83 \\
850 & 87.88 & -4.32 & 38.43 & 38.67 & 96.41 & 2.82 \\
900 & 88.05 & -5.13 & 37.93 & 38.28 & 97.70 & 2.82 \\
950 & 88.74 & -4.96 & 40.22 & 40.52 & 97.03 & 2.82 \\
1000 & 87.40 & -4.53 & 40.62 & 40.87 & 96.36 & 2.81 \\
\hline
\end{tabular}


shades of samples in ceramic glaze are characterized by a yellow colour (Table 6). Compared with the previous methods of synthesis, precipitation provides the deepest yellow shades, especially at the temperature $950^{\circ} \mathrm{C}$ $(C=51.23)$ and $1000^{\circ} \mathrm{C}(C=52.44)$. While calcination temperature grows, hue $H^{\circ}$ declines from $95.01^{\circ}$ to $90.76^{\circ}$ and brightness $L^{*}$ declines from 87.42 to 83.94 . Deeping dark shade of samples corresponds also with decreasing values of bandgap $E_{g}$, which is located in the range $2.70-2.80 \mathrm{eV}$. As interesting dark yellow hue in a ceramic glaze was evaluated sample fired at $1000^{\circ} \mathrm{C}$, among other reasons, that achieve the lowest value of colour coordinates $a^{*}$.

Table 5. Effect of calcination temperature on colour properties of pigment $\mathrm{Bi}_{1.5} \mathrm{Zn}_{0.5} \mathrm{Ce}_{2} \mathrm{O}_{7}$ prepared by $\mathrm{PR}$ and applied into organic matrix in mass tone.

\begin{tabular}{lcccccc}
\hline$T\left({ }^{\circ} \mathrm{C}\right)$ & $L^{*}$ & $a^{*}$ & $b^{*}$ & $C$ & $H^{\circ}$ & $E_{g}(\mathrm{eV})$ \\
\hline 800 & 65.29 & 4.08 & 38.98 & 39.19 & 84.02 & 2.67 \\
850 & 60.80 & 2.64 & 36.90 & 36.99 & 85.91 & 2.66 \\
900 & 54.98 & 2.25 & 32.66 & 32.74 & 86.06 & 2.63 \\
950 & 53.21 & 3.89 & 29.99 & 30.24 & 82.61 & 2.56 \\
1000 & 57.99 & 6.34 & 34.76 & 35.33 & 79.66 & 2.48 \\
\hline
\end{tabular}

Table 6. Effect of calcination temperature on colour properties of pigment $\mathrm{Bi}_{1.5} \mathrm{Zn}_{0.5} \mathrm{Ce}_{2} \mathrm{O}_{7}$ prepared by $\mathrm{PR}$ and applied into ceramic glaze.

\begin{tabular}{lcccccc}
\hline$T\left({ }^{\circ} \mathrm{C}\right)$ & $L^{*}$ & $a^{*}$ & $b^{*}$ & $C$ & $H^{\circ}$ & $E_{g}(\mathrm{eV})$ \\
\hline 800 & 87.42 & -3.51 & 40.03 & 40.18 & 95.01 & 2.80 \\
850 & 86.84 & -3.43 & 43.40 & 43.54 & 94.52 & 2.78 \\
900 & 85.41 & -2.53 & 44.20 & 44.27 & 93.28 & 2.77 \\
950 & 84.39 & -1.48 & 51.21 & 51.23 & 91.66 & 2.71 \\
1000 & 83.93 & -0.70 & 52.44 & 52.44 & 90.76 & 2.70 \\
\hline
\end{tabular}

The particle size distribution of pigments that can significantly affect the colour properties was also measured. The most important value which characterizes particle size and predetermines pigment for various applications is the value $d_{50}$ (median). The samples of $\mathrm{Bi}_{1.5} \mathrm{Zn}_{0.5} \mathrm{Ce}_{2} \mathrm{O}_{7}$ prepared by the solid state reaction (SSR) have the main size value $d_{50}$ in the interval from 6.5 to $8.5 \mu \mathrm{m}$ (Table 7). Specifically, the value $d_{50}$ of pigments grows with the increasing firing temperature up to $900^{\circ} \mathrm{C}$. After the value has a downward trend. A suitable granulometric composition for application of pigments into ceramic glaze is about $5-15 \mu \mathrm{m}$. The span of the distribution in Table 7 informs about the width of the size distribution of the samples. The lowest value (3.1) was achieved at calcination temperature $850^{\circ} \mathrm{C}$. This result confirms that this temperature is suitable for the formation of the dark yellow monodispersive sample.

Results from pigments prepared by suspension mixing (SM) are noticed in Table 7. This method of preparation significantly decreased the particle size $d_{50}$ of the studied pigment the whole temperature range. The values $\left(d_{50}\right)$ are located in a very narrow interval from 2.0 to $2.6 \mu \mathrm{m}$. The values of $d_{50}$ are closer to the desirable size of pigments (less than $2 \mu \mathrm{m}$ ), which are suitable for applications in painting coats. For their potential use in paints, it would be necessary to treat the size mechanically. The span parameter, in this case, is lowest for samples calcined at $800^{\circ} \mathrm{C}$.

From the values presented in Table 7 it is visible that the value $d_{50}$ of pigment prepared by precipitation reaction $(\mathrm{PR})$ is rising with an ascending temperature of calcination. The method of synthesis of the pigment $\mathrm{Bi}_{1.5} \mathrm{Zn}_{0.5} \mathrm{Ce}_{2} \mathrm{O}_{7}$ provides the widest range of value $d_{50}$, namely from 0.7 to $11.8 \mu \mathrm{m}$. This fact can be explained by a significant sintering of samples at temperatures above $900^{\circ} \mathrm{C}$.

\section{CONCLUSIONS}

The influence of the preparation method on the chemical composition, colour properties and particle size distribution of mixed oxide pigment $\mathrm{Bi}_{1.5} \mathrm{Zn}_{0.5} \mathrm{Ce}_{2} \mathrm{O}_{7}$ was investigated. This pigment has been successfully synthesized, having colours ranging from dark yellow via green to bright yellow.

The solid-state reaction (SSR) in terms of colour properties in the organic binder provides the satisfactory dark yellow shade at the calcination temperature $950^{\circ} \mathrm{C}$. The pigment prepared by SSR is multicomponent with additional phases of unreacted initial oxide $\mathrm{Bi}_{2} \mathrm{O}_{3}$ and unidentified phase next to the main fluorite structure of $\mathrm{CeO}_{2}$. For suspension mixing (SM), more significant changes were found for the pigment $\mathrm{Bi}_{1.5} \mathrm{Zn}_{0.5} \mathrm{Ce}_{2} \mathrm{O}_{7}$. There is a significant increase of the values of chroma $(C)$ and the colour coordinate $b^{*}$ in the whole temperature range. It could be summarised that SM

Table 7. An effect of calcination temperature on particle size distribution of pigment $\mathrm{Bi}_{1.5} \mathrm{Zn}_{0.5} \mathrm{Ce}_{2} \mathrm{O}_{7}$ prepared by SSR, SM and PR.

\begin{tabular}{|c|c|c|c|c|c|c|c|c|c|c|c|c|}
\hline \multirow[b]{2}{*}{$T\left({ }^{\circ} \mathrm{C}\right)$} & \multicolumn{4}{|c|}{ SSR } & \multicolumn{4}{|c|}{ SM } & \multicolumn{4}{|c|}{ PR } \\
\hline & $\mathrm{d}_{10}(\mu \mathrm{m})$ & $\mathrm{d}_{50}(\mu \mathrm{m})$ & $\mathrm{d}_{90}(\mu \mathrm{m})$ & span & $\mathrm{d}_{10}(\mu \mathrm{m})$ & $\mathrm{d}_{50}(\mu \mathrm{m})$ & $\mathrm{d}_{90}(\mu \mathrm{m})$ & span & $\mathrm{d}_{10}(\mu \mathrm{m})$ & $\mathrm{d}_{50}(\mu \mathrm{m})$ & $\mathrm{d}_{90}(\mu \mathrm{m})$ & span \\
\hline 800 & 0.7 & 6.5 & 21.2 & 3.2 & 0.5 & 2.4 & 8.6 & 3.3 & 0.3 & 0.7 & 5.6 & 7.6 \\
\hline 850 & 0.8 & 7.2 & 22.9 & 3.1 & 0.6 & 2.6 & 11.7 & 4.4 & 0.3 & 1.1 & 13.6 & 12.2 \\
\hline 900 & 1.0 & 8.5 & 32.0 & 3.7 & 0.5 & 2.4 & 13.2 & 5.3 & 0.4 & 2.2 & 14.6 & 6.5 \\
\hline 950 & 1.0 & 7.9 & 26.9 & 3.3 & 0.4 & 2.1 & 10.8 & 5.0 & 0.7 & 5.6 & 24.4 & 4.2 \\
\hline 1000 & 0.8 & 8.0 & 34.4 & 4.2 & 0.3 & 2.0 & 13.6 & 6.5 & 1.2 & 11.8 & 80.5 & 6.7 \\
\hline
\end{tabular}


method of preparation provides a very dark yellow at the lower temperature, i.e. $800^{\circ} \mathrm{C}$, as compared to SSR. This method also has a very positive effect on the particle size distribution of the synthesized samples, where $d_{50}$ in the interval approx. $2.0-2.6 \mu \mathrm{m}$. As a consequence of this result, the compounds are suitable for application in paints (after necessary grinding). X-ray diffraction analysis confirmed the cubic $\mathrm{CeO}_{2}$ phase with a small amount of a secondary unidentified phase. The most appropriate method for the formation of dark yellow hues in ceramic glaze was selected the precipitation reaction (PR). In this case, dark yellow hues were achieved at the highest temperatures 950 and $1000^{\circ} \mathrm{C}$. The value of $d_{50}(5.6$ and $11.8 \mu \mathrm{m})$ is consistent with the requirements for use of the pigment for ceramic purposes. From the viewpoint of $\mathrm{X}$-ray diffraction analysis there were identified phases of cubic $\left(\mathrm{Ce}_{0.8} \mathrm{Bi}_{0.2}\right)$ $\mathrm{O}_{1.9}$ and tetragonal $\mathrm{Bi}_{2} \mathrm{O}_{3}$. The results of XRD analysis of sample $\mathrm{Bi}_{1.5} \mathrm{Zn}_{0.5} \mathrm{Ce}_{2} \mathrm{O}_{7}$ prepared by SSR, SM and PR are not single phases. Some pigments that are commercially used in the industry are multi-phase. The present phases did not affect the colour and application properties of the pigment.

Generally, it depends on the application area of the pigment and then it is necessary to appropriately select the method of preparation in which the formed coloured interesting yellow shades. The compound $\mathrm{Bi}_{1.5} \mathrm{Zn}_{0.5} \mathrm{Ce}_{2} \mathrm{O}_{7}$ is potentially important dark yellow pigment worthy of large-scale industrial testing.

\section{Acknowledgements}

This work has been supported by University of Pardubice under the project SGS_2016_014.

\section{REFERENCES}

1. Faulkner E.B., Schwartz R.J. (2009). High Performance Pigments. $2^{\text {nd }}$ ed. Weinheim: Wiley.

2. Kumari L.S., Rao P.P., Koshy P. (2010): Red pigments based on $\mathrm{CeO}_{2}-\mathrm{MO}_{2}-\mathrm{Pr}_{6} \mathrm{O}_{11}(\mathrm{M}=\mathrm{Zr}$ and $\mathrm{Sn})$ : solid solutions for the coloration of plastics. Journal of the American Ceramic Society, 93, 1402-1408. doi:10.1111/j.1551-2916. 2009.03569.x

3. Buxbaum G., Pfaff G. (2005). Industrial inorganic pigments. $3^{\text {rd }}$ ed. Weinheim: Wiley.

4. Šulcová P., Gorodylova N. (2015).: Compopunds based on doped $\mathrm{Bi}_{2} \mathrm{O}_{3}$ : new ecologically friendly yellow-orange shade pigments. Encyclopedia of Information Science and Technology. $3^{\text {rd }}$ ed. IGI Global. pp. 2844-2853. doi:10.4018/ 978-1-4666-5888-2.ch278

5. Oudghiri-Hassani H., Rakass S., Al Wadaani F.T., AlGhamdi K.J., Omer A., Messali M., Abboudi M. (2015): Synthesis, characterization and photocatalytic activity of
$\alpha-\mathrm{Bi}_{2} \mathrm{O}_{3}$ nanoparticles. Journal of Taibah University for Science, 9, 508-512. doi:10.1016/j.jtusci.2015.01.009

6. Xiaohong W., Wei Q., Weidong H. (2007): Thin bismuth oxide films prepared through the sol-gel method as photocatalyst. Journal of Molecular Catalysis A: Chemical, 126, 167-171. doi:10.1016/j.molcata.2006.08.016

7. Huang Ch.-Ch., Fung K.-Z. (1999).: Effect of moisture on the phase stability of $\mathrm{Y}_{2} \mathrm{O}_{3}-\mathrm{Bi}_{2} \mathrm{O}_{3}$ solid electrolytes. Solid Oxide Fuel Cells (SOFC VI): Proceedings of the Sixth International Symposium. The Electrochemical Society, Inc. New Jersey. pp 254-263.

8. Drache M., Roussel P., Wignnacourt J.-P. (2007): Structures and oxide mobility in $\mathrm{Bi}-\mathrm{Ln}-\mathrm{O}$ materials: heritage of $\mathrm{Bi}_{2} \mathrm{O}_{3}$. Chemical Reviews. 107, 80-96. doi:10.1021/cr050977s

9. Harwing H.A. (1978): On the structure of bismuthsesquioxide: the $\alpha, \beta, \gamma$, and $\delta$-phase. Zeitschrift für anorganische und allgemeine Chemie. 444, 151-166.

10. Gonzalvo B., Romero J., Fernández F., Torralvo M.J. (2001): $(\mathrm{Bi}, \mathrm{R})_{2} \mathrm{O}_{3}(\mathrm{R}: \mathrm{Nd}, \mathrm{Sm}$ and Dy) oxides as potential pigments. Journal of Alloys and Compounds, 232-324, 372-375. doi:10.1016/S0925-8388(01)01056-8

11. ThompsonM., Herranz T., Santos B., Marco J.F., Berry F.J. Greaves C. (2010): The ionic conductivity and local environment of cations in $\mathrm{Bi}_{9} \mathrm{ReO}_{17}$. Journal of Solid State Chemistry, 183, 1985-1991. doi:10.1016/j. jssc.2010.06.017

12. Trivedi M.K., Tallapragada R.M., Branton A., Trivedi D., Nayak G., Latiyal O., Jana S. (2015): Evaluation of atomic, physical, and thermal properties of bismuth oxide powder: an impact of biofield energy treatment. American Journal of Nano Research and Applications, 3(6), 94-98. doi:10.11648/j.nano.20150306.11

13.Stránská L., Šulcová P., Vlček M. (2013): Synthesis and properties of inorganic pigments based on pyrochlore compounds with different lanthanides. Journal of Thermal Analysis and Calorimetry, 113, 127-135. doi:10.1007/ s10973-013-3037-z

14.CIE. Recommendations on uniform colour spaces, colour difference equations, psychometrics colour terms. In Supplement No. 2 of CIE Publ. No. 15 (E1-1.31) 1971. Paris: Bureau central de la CIE; 1978.

15.Völz H.G. (2002). Industrial color testing: fundamentals and techniques. $2^{\text {nd }}$ ed. Weinheim: Wiley.

16. Sreeram K.J., Srinivasan R., Devi J.M., Nair B.U., Ramasami T. (2007): Cerium molybdenum oxides for environmentally benign pigments. Dyes and Pigments, 75 , 687-692. doi:10.1016/j.dyepig.2006.07.021

17. Yang J., Shahid M., Zhao M., Feng J., Wan Ch., Pan W. (2016): Physical properties of $\mathrm{La}_{2} \mathrm{~B}_{2} \mathrm{O}_{7}(\mathrm{~B}=\mathrm{Zr}$, Sn, Hf and $\mathrm{Ge}$ ) pyrochlore: First-principles calculations. Journal of Alloys and Compounds, 663, 834-841. doi:10.1016/j. jallcom.2015.12.189

18. Olazcuaga R., Le Flem G., Alarcón J. (1993): Evolución crómatica del pigmento $\mathrm{Ce}_{0.95} \mathrm{Pr}_{0.05} \mathrm{O}_{2}$ : del rojo al amarillo. Boletín de la Sociedad Española de Cerámica y Vidrio, 32, 251-254.

19. Joint Committee on Powder Diffraction Standards. International centre of diffraction data. Swarthmore, PA, USA; 2012. 